\title{
Inclusive Library Service to Individuals with Mental Illnesses and Disorders
}

Michelle P. Green, University of Wyoming, USA

\begin{abstract}
What does it mean to have a mental illness? According to the National Alliance on Mental Illness, it is a condition affecting a person's mood, emotions, or thinking and can interfere with a person's ability to relate to others and function in their daily life. Mental illness of any kind affects approximately $18 \%$ of the United States adult population-around 45 million people, as of 2016.

Why does this matter to librarians and other information professionals? Librarians are likely to unknowingly encounter someone with mental illness, as one cannot simply look for violent or disruptive behavior in every case. This article briefly examines the literature to highlight what is being done in both public and academic libraries to meet the information needs of individuals with mental illness or any type of mental health issue. It suggests ways to improve service to and advocate for the information needs of these invisibly disabled patrons.
\end{abstract}

Keywords: advocacy; libraries; mental health; mental illness; service

Publication Type: special section publication

\section{Introduction}

M ental illnesses affect approximately $18 \%$ of the United States adult population (National Institute of Mental Health, 2019). Mental illness is a condition affecting a person's mood, emotions, or thinking and can interfere with a person's ability to relate to others and function in their daily life (National Alliance on Mental Illness, 2018). The official diagnostic manual of the American Psychiatric Association, Diagnostic and Statistical Manual of Mental Disorders, 5th edition (2013), offers definitions and diagnostic criteria for a variety of mental disorders and conditions. Within the general definition of mental illness or mental disorder are specific conditions and disorders, such as schizophrenia, bipolar disorder, anxiety disorders, eating disorders, impulse control and addiction disorders, personality disorders, obsessivecompulsive disorders, and post-traumatic stress, among other conditions.

At some point in their careers, librarians and other information professionals are likely to provide information and services to serve individuals with varying mental health issues, psychiatric disabilities, or neurodiversities whether those issues and diversities are apparent or not. Libraries not only provide information about mental illnesses to library users and their support communities, but they can also be a place of social inclusion, with a real effect on general community levels of tolerance for people with mental illness.

In the U.S. in 2016, just over $43 \%$ of adults affected by mental illnesses sought treatment

The International Journal of Information, Diversity, \& Inclusion, 4(1), 2020

ISSN 2574-3430, https://jps.library.utoronto.ca/index.php/ijidi

DOI: $10.33137 /$ ijidi.v4i1.32500 
(National Institute of Mental Health, 2019). Treatment here is defined as inpatient or outpatient treatment or counseling and/or prescription medication specifically designed for treatment of mental health or substance abuse conditions. While not all mental health issues necessitate formal counseling or medication, the emotional, social, and psychological support available from mental health professionals and the resources they can provide can help individuals with selfacceptance and self-esteem, increase confidence and communication, enhance problem solving skills, and reduce some of the risks associated with mental illnesses and disorders (Mental Health America, n.d.).

A 2014 article on the impact of mental illness stigma on individuals seeking and participating in mental health care notes that social discrimination based on mental illness can lead to selfstigma, thus hampering progress in treatment and recovery efforts (Corrigan, Druss, \& Perlick, 2014). It is worth noting that fewer 18- to 25-year olds (around 35\% of 18-25 years with mental health issues) sought treatment for mental health issues than did 26- to 49-year olds (just over 43\%) (National Institute of Mental Health, 2019). In spite of recent popular discussion around mass shooters, in which commentators debate the role of mental illnesses and disorders in acts of violence, those with serious mental disorders who may be inclined to outbursts or violence amount to only $4.2 \%$ of the adult population of individuals with mental illnesses (National Institute of Mental Health, 2019). Even then, those in that group are only slightly more likely to be violent, generally attributed to the influence of illicit drugs or alcohol or being off medication or untreated (Hiday, 2006; Neilssen et al., 2011; Swanson, 2011). Both social stigma (i.e., social cues of disapproval and discrimination) and structural stigma (i.e., associated with social and institutional policies) can undermine opportunities for people to seek help and support.

This article will discuss the important role libraries can take in creating inclusive services and supportive environments for individuals with mental health variations. The article demonstrates the strong presence of libraries in partnering with the community for mental health and mental illness services and suggests ways that libraries and library professionals might benefit from that literature as we work to expand understanding of mental illness in librarianship and create more inclusive communities.

\section{What Libraries Are Doing Right and What We Can Learn}

As champions of critical thinking, progressive thought, and information literacy, librarians are uniquely poised to help eliminate the stigma of mental illness through advocacy for users and employees, education and awareness, and even through continued emphasis on stress relief and general well-being. With the growing emphasis on academic librarians' role in student wellness and mental health, college and university libraries are doing more to accommodate the needs of individuals with mental illness. Accommodations for physical disability, whether invisible or visible, are required by the Americans with Disabilities Act, and it is not uncommon to see adjustable tables and desks, captioning, the provision of note taking software and devices, or American Sign Language interpreters. All these allow for greater access to learning and information for the individuals who need it. While accommodation for mental illness, such as testing accommodations for anxiety disorders, is included in various parts of the Americans with Disabilities Act (U.S. Department of Justice, 2010), a search of the relevant literature reveals a gap in in library assistance for people with mental illness. The Association of Specialized and Cooperative Library Agencies of the American Library Association published a report in 2007 which set guidelines for serving library patrons with mental illness. The report stresses the important role of all librarians to reduce discrimination, share information, and provide

The International Journal of Information, Diversity, \& Inclusion, 4(1), 2020

ISSN 2574-3430, jps.library.utoronto.ca/index.php/ijidi/index

DOI: $10.33137 /$ ijidi.v4i1.32500 
programming.

As a resource to the local community, a public library might serve a range of users affected by mental illness including veterans, homeless individuals, children, teenagers, and adults young and old (Brewster, 2014). More and more often these days, public libraries provide community health and wellness information in many formats (such as print, digital, or audio), including, in some cases, partnerships with groups like United Way to connect community members to local resources and information (Cathcart, 2008). Since the late 1800s, American public librarians have disseminated health information and now also serve as de facto social workers and counsellors. This is true internationally, as well (Rubenstein, 2012). As noted by a public health professional (Wahowiak, 2018, p. 12), "As people are more likely to visit their [local public] library than a doctor, health advocates have an opportunity to reach people where they live and learn. Libraries are free, accessible to everyone and are key points of community engagement-making them the perfect partner for public health programs and education."

Based on the statistics about adult mental illness provided in the introduction, most university and college librarians have probably regularly assisted, taught, or otherwise interacted with at least some undergraduate or postgraduate learners or colleagues with mental health issues. In some cases, such as in law libraries, there is the additional interaction with highly stressed students who are possibly suffering from temporary mental health issues that can sometimes lead to substance abuse later in life (Marullo Anzalone \& Vann, 2018). Beyond finding a place to study and accessing information for assignments, there is no doubt students use their time in the library to watch videos, surf the Web, and look up health and wellness information. Some academic libraries provide compiled health resources, such as subject guides filled with local resources and helpful information. The trend of focusing on student wellness is increasing in academic libraries with finals weeks stress relief activities, animal therapy visits, and expanded operating hours for extra studying time, with one librarian even promoting the value of nap stations so students can benefit from extra sleep during stressful times of the semester (Ramsey \& Aagard, 2018; Wise, 2018).

Lisl Walsh (2017) describes life with mental illness as an academic in the American university system and the intersection of mental illness and scholarly production, resulting in affected academics seeming "lazy," among other things. The effects of some mental illnesses (e.g., anxiety, depression, obsessive re-thinking, self-doubt) very likely limits the presence of applicable literature in peer-reviewed journals, as those writing from a place of personal experience are less likely to be represented due to health limitations and typically stringent timelines and requirements. Furthermore, does the lack of literature on mental health or illness also reflect an overall silence in academia regarding mental illness, a preference for the ableminded or so-called "typical" thinkers?

Likewise, some public libraries have embraced their status as community servants and de facto counsellors through the programs they offer, such as libraries in Scandinavia who provide mental health and wellness services to their patrons (Bjorn Hansen, et. al., 2016; Berg Larsen, 2015). One library in Ireland came up with a "book prescription scheme" aimed to get self-help books into the hands of individuals with mild to moderate mental illness (Neville, 2014). They collected data on this bibliotherapy service as they implemented the program and found some interesting results. For instance, while the librarians in the program understood their role was not one of formal counseling or treatment, they magnified their role as the curators and disseminators of accurate mental health information. They did not receive formal mental health training but

The International Journal of Information, Diversity, \& Inclusion, 4(1), 2020

ISSN 2574-3430, jps. library.utoronto.ca/index.php/ijidi/index

DOI: $10.33137 /$ ijidi.v4i1.32500 
naturally assumed the role of advocates for the importance of mental health treatment. The staff seemed to clearly understand their role was not to pick up slack for poor services in their local community, but their efforts did recommend an expanded mental health collection and provide library staff with deeper understanding of the contents of their mental health collection. This Irish public library program highlights an important point: While librarians of all types may end up serving as ad hoc social workers or counsellors, they are not meant to be a treatment plan or counseling coordinator. Rather, programs like this illustrate the librarian's role as a facilitator and resource. For those with mental illness, a library can be a starting place for getting help but should never be the only source. Public libraries can embrace their excellent positioning and importance in the community to contribute to general population health, which also includes mental health awareness. Through resources, services, and activities, these potential community health partners tend to consistently have their finger on the community pulse. They can provide timely and free mental health and general wellness resources to the surrounding community.

Academic libraries, on the other hand, are not as present in the literature of best practices for offering mental health support to users. On the surface, this can appear to indicate little is being done, but that is not necessarily the case. Typically, based on the literature, most academic library mental health outreach or aid takes the form of general student wellness programs. One article discusses this trend, noting the evidence in support of increased retention and student success when wellness programs are in place (Ramsey \& Aagard, 2018). One example of a successful partnership between an academic and public library is the Healthy Library Initiative (Morgan et. al., 2016). This is a partnership between the University of Pennsylvania and their public library system in the surrounding Philadelphia area, the Free Library of Philadelphia. Evaluative research related to this initiative assessed the impact of ten very well-attended events and the impact on social health determinants in the community. One of the groups that received targeted support was individuals with mental illnesses who participated in the targeted social literacy events. The study found that libraries are "trusted institutions" that reach large numbers and varieties of people, and because of this trait, they are poised to positively impact population health, including mental illness (p. 1).

College and university libraries are increasingly hosting pet therapy sessions, particularly during finals week. Some libraries hold meditation sessions of various types, and provide meditation rooms, such as that found at Humboldt State University, or "reflection rooms," such as at the University of Kansas (Wachter, 2018). One article from the University of Toronto Library and Information Science program discusses the use of this type of meditation in the classroom, easily applied to a library event or even a one-shot instructional library session (Hartel, Nguyen, \& Guzik, 2017). Another article (Wise, 2018) extolls the benefits, particularly in the long term, of adding napping stations in the library. Looking at the impact of sleep deprivation on college students, the author examines the potential and evidential damage to students' minds and college careers. There are, however, benefits beyond student wellness for students, faculty, and staff who struggle with mental illness. These napping stations and meditation and reflection rooms provide a safe space for individuals who experience panic attacks, get easily overwhelmed or overstimulated, or any other manifestation of their mental disorder.

The high stress environment of law school is another arena in which academic libraries are increasing their efforts. Two authors describe the programs at their law school library and the ways in which they reach out to the students through their positions as librarians (Marullo Anzalone \& Vann, 2018). They describe one 2016 report in which over 14\% of lawyers admit that their substance abuse began during law school, a concerning statistic (p. 44). Marullo Anzalone

The International Journal of Information, Diversity, \& Inclusion, 4(1), 2020

ISSN 2574-3430, jps.library.utoronto.ca/index.php/ijidi/index

DOI: $10.33137 /$ ijidi.v4i1.32500 
and Vann suggest law librarians are poised to contribute to law student well-being due to their position as information gatekeepers and providers. At minimum, law librarians (and other information professionals) can provide resource lists and add to the collection books and journals that focus on mental health and general well-being.

Harrell and Guyer (2015) also illustrate the work law librarians are doing to serve students with mental illnesses. Their article offers 10 suggestions for harnessing a library's customer focus to include those with mental health issues. They suggest extending quality customer service, staying informed, and protecting patron privacy, among other tips. The authors also illustrate creative service through an example. At one of the authors' libraries, they set aside the volumes most frequently used by one patron with mental illness so he could find them more easily on his daily visits. The staff also wrote down the locations of each book in the event they got shelved. "This simple accommodation," notes Guyer, allowed their library "to better serve a patron with a mental illness" (p. 24).

Harrell and Guyer remind all librarians to stay informed about regulations and laws as well as standards and best practices. However, there are few official and national standards in place that provide guidance for any type of library. Hecker (1996) suggests patrons with mental illness should not be treated in the category of "problem patrons" but rather, according to the standards of the Americans with Disabilities Act, with understanding and accommodation, just as one would with someone with a visible indicator of disability such as a wheelchair or white cane. The Association of Specialized and Cooperative Library Agencies' (2007) Guidelines for Library Services for People with Mental Illnesses best practices guide and its accompanying tip sheet (2010) have helped establish formal guidelines for library services to people with mental illness, keeping in mind Americans with Disabilities Act principles. Libraries of all types can use this guide as a baseline to set their own standards or best practices for serving patrons with permanent or temporary mental illness. Academic libraries in particular can use the ideas of public librarians, such as increasing collection holdings on mental health topics, being aware of local mental health resources, or even just existing as a place of safety and comfort. Of course, this must be done with caution and awareness of local resources.

\section{Recommendations and Conclusions}

Even with restrictions such as a low budget or poor staffing, any librarian or information professional can make improvements to their institution's service to individuals with mental illness. Find out if there are policies in place, whether general or specific, and examine them for dated language or approaches and other red flags. If there are no policies in place, consider devising a standard of practice, however general. Consider utilizing existing spaces meant for wellness (such as napping stations or a meditation room/area) as safe areas for people who may need a calming space to come down from a panic attack or sensory overload. If the collection budget is poor, highlight the extant books in the collection on mental health, self-help, meditation, and similar topics. Promote days or months relating to mental health awareness or particular conditions and coordinate displays to bring awareness to the topics.

If a stronger advocacy role is desired, contact Human Resources (or other applicable departments) to inquire about any mental health or mental illness trainings, including webinars and seminars. Additionally, many information professionals receive CPR and first aid training, which covers physical emergencies they may encounter. Very few people receive mental health first aid training, which can equip library employees to better diffuse tense situations, identify

The International Journal of Information, Diversity, \& Inclusion, 4(1), 2020

ISSN 2574-3430, jps.library.utoronto.ca/index.php/ijidi/index

DOI: $10.33137 /$ ijidi.v4i1.32500 
and provide the right resources, and help patrons through a troubling time or incident. Depending on location, there may be mental health first aid programs operated by a variety of organizations. Mental Health First Aid USA, operated by the National Council for Behavioral Health, is one of the more prominent organizations conducting these trainings. Participants learn how to recognize a variety of mental illnesses and substance abuses and are then given a five-step action plan (Throgmorton, 2017).

As this article has demonstrated, there is a lack of peer-reviewed, academic literature on library services to individuals with mental illness or mental health conditions. One important way to remedy this is the creation of more peer-reviewed literature. Librarians engaged in research or academic librarians required to produce scholarly works are in a particularly prime position to contribute. Empirical study and investigation are needed in all areas and all types of libraries, especially college and university libraries. Studies are needed that go beyond the current focus on general mental health and wellness, student stress, etc. While studying mental health or illness is usually sensitive, there are ways to mask identifying data. The importance of additional literature in this area cannot be understated. Deeper research provides deeper understanding and more meaningful service for individuals managing mental health conditions.

The lack of literature about what academic libraries are doing to serve patrons with mental illness can appear to be discouraging. In reality, it indicates only that not much has been published on these efforts if they do exist. While general mental health and personal wellbeing are gaining prominence in the national conversation, one can still casually observe the stigma that still surrounds mental illness. Something as seemingly innocuous as saying the weather is "bipolar" or referring to a particularly tidy friend as "OCD" can do more damage than one realizes. Information professionals, as gatekeepers of information and its access, are situated to have a positive impact on patrons with mental illness and other invisible disabilities. Through even small efforts and changes they can positively contribute to a positive national conversation. Even to make a difference in the life of one patron is reason to engage in and promote better service to individuals who are not so obviously different.

\section{References}

American Psychiatric Association. (2013). Diagnostic and statistical manual of mental disorders (5th ed.). Arlington, VA: American Psychiatric Publishing. doi:10.1176/appi.books. 9780890425596

Association of Specialized and Cooperative Library Agencies. (2007). Guidelines for library services for people with mental illnesses. Chicago, IL: American Library Association.

Association of Specialized and Cooperative Library Agencies. (2010). People with mental health issues: What you need to know: Library Accessibility Tip Sheet 7. Retrieved from http://www.ala.org/asgcla/sites/ala.org.asgcla/files/content/asclaprotools/accessibil itytipsheets/tipsheets/7-Mental_Illlness.pdf

Berg Larsen, E. (2015). Stronger mental health. Scandinavian Library Quarterly, 48(1/2), 26-29. Retrieved from http://slq.nu/wp-content/uploads/2015/06/SLQ-1-2.pdf.

The International Journal of Information, Diversity, \& Inclusion, 4(1), 2020 
Bjorn Hansen, L., Thybo, P., \& Lundsgaard-Leth, M. (2016). The library plays an active part in issues of healthcare. Scandinavian Library Quarterly, 49(1/2), 18-21. Retrieved from http://slq.nu/wp-content/uploads/2016/06/SLQ-1-2.14.6.pdf.

Brewster, L. (2014). The public library as therapeutic landscape: A qualitative case study. Health \& Place, 26(2014), 94-99. Retrieved from http://www.sciencedirect.com/science/article/pii/S1353829213001792

Cathcart, R. (2008). Librarian or social worker: Time to look at the blurring line? The Reference Librarian, 49(1), 87-91. doi:10.1080/02763870802103845

Corrigan, P. W., Druss, B. G., \& Perlick, D. A. (2014). The impact of mental illness stigma on seeking and participating in mental health care. Association for Psychological Science. Retrieved from https://www.psychologicalscience.org/publications/mental-illnessstigma.html

Harrel, N. \& Guyer, C. (2015). Mental illness in the library: Ten tips to better serve patrons. AALL Spectrum, 2015(February), 22-25.

Hartel, J., Nguyen, A. \& Guzik, E. (2017). Mindfulness meditation in the classroom. Journal of Education for Library \& Information Science, 58(2), 112-115. https://doi.org/10.3138/jelis.58.2.112

Hecker, T. E. (1996). Patrons with disabilities or problem patrons: Which model should librarians apply to people with mental illness? Reference Librarian, 25(53), 5-12. https://doi.org/10.1300/J120v25n53_02

Hiday, V. A. (2006). Putting community risk in perspective: A look at correlations, causes and controls. International Journal of Law and Psychiatry, 29(4), 316-331. doi:10.1016/j.ijlp.2004.08.010

Mental Health America. (n.d.). Therapy. Retrieved from https://www.mentalhealthamerica.net/therapy

Marullo Anzalone, F., \& Vann, C. (2018). Mental health and the role of the law librarian: How law librarians and lawyer assistance programs can help lawyers and law students cope with mental health issues. AALL Spectrum, 22(4), 43-48.

Morgan, A. U., Dupuis, R., D’Alonzo, B., Johnson, A., Graves, A., Brooks, K. L., McClintock, A., Klusaritz, H., Bogner, H., Long, J., Grande, D., \& Cannuscio, C. C. (2016). Beyond Books: Public Libraries As Partners For Population Health. Health Affairs; Chevy Chase, 35(11), 2030-2036. http://dx.doi.org/10.1377/hlthaff.2016.0724

National Institute of Mental Health. (2019). Mental illness. Retrieved from https://www.nimh.nih.gov/health/statistics/mental-illness.shtml

National Alliance on Mental Illness. (2018). Mental Health Conditions. Retrieved from https://www.nami.org/Learn-More/Mental-Health-Conditions.

Neville, P. (2014). Librarian or counsellor? A pilot study of the experiences of library staff in

The International Journal of Information, Diversity, \& Inclusion, 4(1), 2020

ISSN 2574-3430, jps.library.utoronto.ca/index.php/ijidi/index

DOI: $10.33137 /$ ijidi.v4i1.32500 
one healthy reading scheme in Ireland. Journal of Mental Health, 23(1), 15-19. doi: $10.3109 / 09638237.2013 .815332$

Nielssen, O., Bourget, D., Laajasalo, T., Liem, M., Labelle, A., Hakkanen-Nyholm, H., \& Large, M. M. (2011). Homicide of strangers by people with a psychotic illness. Schizophrenia Bulletin, 37(3), 572-579. doi:10.1093/schbul/sbp112

Ramsey, E. \& Aagard, M. C. (2018). Academic libraries as active contributors to student wellness. College \& Undergraduate Libraries, 25(4), 328-337. doi:10.1080/10691316.2018.1517433

Rubenstein, E. (2012). From social hygiene to consumer health: Libraries, health information, and the American public from the late nineteenth century to the 1980s. Library \& Information History, 28(3), 202-219. doi:10.1179/1758348912Z.00000000016

Swanson, J. (1994). Mental disorder, substance abuse, and community violence: An epidemiologic approach. In J. Monahan \& H. J. Steadman (Eds.), Violence and mental disorder: Developments in risk assessment (pp. 101-136). Chicago, IL: University of Chicago Press.

Swanson, J. (2011). Explaining rare acts of violence: The limits of evidence from population research. Psychiatric Services, 62(11), 1369-1371. doi:10.1176/ps.62.11.pss6211_1369

Throgmorton, K. (2017). Mental health first aid. American Libraries; Chicago, 48(3/4), 22-23.

U.S. Department of Justice. (2010). Testing accommodations. Retrieved from https://www.ada.gov/regs2014/testing_accommodations.pdf

Wachter, R. (2018, January 2). A space apart: College libraries contemplate meditation rooms. American Libraries. Retrieved from https://americanlibrariesmagazine.org/2018/01/02/library-meditation-rooms-spaceapart/

Wahowiak, Lindsey. Libraries, public health work together on community health: Settings serve as community hubs. The Nation's Health; Washington 48(8) (October 2018): 1-12.

Walsh, L. (2017). Academia is irreparably ableist. Retrieved from https://medium.com/@lislanna/academia-is-irreparably-ableist-925fb33721ff

Wise, M. J. (2018). Naps and sleep deprivation: Why academic libraries should consider adding nap stations to their services for students. New Review of Academic Librarianship, 24(2), 192-210. doi:10.1080/13614533.2018.1431948

Michelle Green (mgreen25@uwyo.edu) is the Learning and Engagement Librarian at the University of Wyoming. She holds a Master of Library and Information Science degree from the University of Oklahoma. Michelle has a strong interest in critical librarianship, diversity, and mental illness advocacy.

The International Journal of Information, Diversity, \& Inclusion, 4(1), 2020 